\title{
Reverse-Osmosis Desalination of Water Powered by Photo-Voltaic Modules
}

\author{
Ammar Alkhatib \\ Energy Engineer, Ismaning, Germany \\ Email: alkhatibammar@hotmail.de
}

Received November 1, 2013; revised December 1, 2013; accepted December 8, 2013

Copyright (C) 2014 Ammar Alkhatib. This is an open access article distributed under the Creative Commons Attribution License, which permits unrestricted use, distribution, and reproduction in any medium, provided the original work is properly cited. In accordance of the Creative Commons Attribution License all Copyrights (C) 2014 are reserved for SCIRP and the owner of the intellectual property Ammar Alkhatib. All Copyright (C) 2014 are guarded by law and by SCIRP as a guardian.

\section{ABSTRACT}

The rising of the world's population leads automatically to the rising of water demand. As a consequence the lack of drinking water increases. Currently, approximately 1.2 billion people globally (one-sixth of the world's population) do not have access to adequate clean water. Since a large part of the world's population is concentrated in coastal areas, the desalination of seawater seems to be a promising solution, especially in our Arab world. An innovative stand-alone solar desalination system could be used to produce drinking water from seawater or any brackish water sources. The great advantage of such a system is that it combines efficient desalination technology, reverse osmosis, with a renewable energy source; the main goal is improving the technical feasibility of such systems. There are many advantages of this coupling with RE resources; first of all we separate the drinking water from the electricity grid and its faults, save the burning fossil fuel and its emissions and can provide fresh water to remote communities that do not have sufficient traditional energy sources; but as we see in the thesis we don't have economic benefit; because these projects depend on the electricity cost in each country and its location and its solar specifications. We design and implement a small laboratorial model for PV-RO (Photo-Voltaic Powered Reverse Osmosis) to recognize the its performance for seawater and brackish water; many of the problems are interrupted such as embargo on Syria; so we see this project has to be done according to affordable local potentialities, but we crave to keep the principle of operation, so we make it for the tap water which close to brackish.

\section{KEYWORDS}

Photo-Voltaic; Desalination; Reverse Osmosis

\section{Introduction}

Access to clean water is quickly becoming a significant worldwide problem. Currently, approximately 1.2 billion people globally (one-sixth of the world's population) do not have access to adequate clean water. Many more people face shortages during the summer. With current rates of population growth and the effects of global warming, the problem of access to clean water is expected to grow. The problem is exacerbated by the growing need for cleaning alternative energy. Energy is the key component to produce clean water in many locations. Many of the populated regions with limited clean water supplies are located in coastal regions with ability to access to an abundance of seawater. Furthermore, arid inland areas often have access to brackish groundwater. Desalination is a natural solution for these regions. In densely populated areas, large-scale desalination plants can be built to provide an adequate water supply. While the energy to power these plants is often a limiting factor, these areas have a number of potential solutions.

For small communities in remote areas with limited natural water supplies, very large desalination plants are not a viable solution. These areas that are outside the major electrical grids rely on transported water or smallscale desalination plants. Desalination is an energy intensive process and to meet these energy requirements, diesel generators are commonly used. However, diesel generators pollute the environment and can be expensive. 
Arid areas also typically have high insulation. This makes these locations good candidates for solar energy systems. Hence, using clean, renewable solar energy to produce clean water would be ideal for these communities.

For large communities, solar thermal desalination systems have potential. However, this technology is not easily scaled for communities that have lower water demands. For smaller communities, photovoltaic reverse osmosis (PVRO) is a potential solution. PVRO has minimal environmental impact, can be easily designed and assembled for different demand profiles using modular components, and can be easily maintained and repaired. However, to have a potential water solution for small communities and remote areas, PVRO must be cost effective. The total lifetime costs of PVRO plants vary substantially by the location due to variations in solar resources, water types.

In this paper, a method for determining the engineering feasibility for community-scale PVRO systems is developed. A PVRO system is feasible engineering if it is both technically and economically feasible. Technical feasibility of community-scale PVRO systems has been established. Economic feasibility for the PVRO system is established based on a cost comparison with equivalent water supply methods for remote locations. Several examples of illustrating application are presented to both remote and populated areas.

In this paper, we will present the components of PVRO systems and we will see the performance of these systems with solar radiation variations.

\section{PV-RO Demonstration Systems}

The osmotic pressure of seawater is much higher than that of the brackish water, and therefore its desalination requires much more energy, and, unavoidably, a rather bigger PV array. Also, the higher pressures found in seawater RO systems require use of mechanically stronger components. Thus, the total cost of water from seawater PV-RO is likely remains higher than that from brackishwater, and systems have not yet passed the demonstration stage.
The Lampedusa seawater PV-RO demonstration was a flagship project commissioned in 1990, with a very large PV array and battery bank. It includes an energy-recovery turbine of modest efficiency, and achieved a specific energy consumption of around $5.5 \mathrm{kWh} / \mathrm{m}^{3}$. Since 1995, the PV has been supplemented by mains electricity. The CRES and ITC projects are current, neither have energy-recovery. The project at La Paz is particularly interesting (Kunczynski 2003). It has included trial of three energy-recovery mechanisms: a small ERI's Pressure Exchanger, several Clark pumps and, most recently, the Danfoss hydraulic motor (Danfoss 2002). The test site has a large PV array and battery bank and the PV array size shown in Table 1 is based on the measured electrical power consumption of the RO system [1].

\section{The Component of PV-RO Systems}

These systems consist of many parts, we will mention, as in the Figure 1:

- $\quad$ Reverse osmosis stack.

- $\quad$ High pressure pump.

- DC motor.

- $\quad$ Storage batteries.

- PV modules.

The Main components in these systems are two: RO stack and PV modules. We will discuss the details about them despite that the rest of the components are so important, and known for ages before RO and PV components [2].

\subsection{Reverse Osmosis Stack}

A semi permeable membrane, like the membrane of a cell wall or a bladder, is selective about what it allows to pass through, and what it prevents from passing. These membranes in general make water pass very easily because of its small molecular size; but also prevent many other contaminants from passing by trapping them. Water will typically be presented on both sides of the membrane, with each side having a different concentration of dissolved minerals. Since the water in the less concentrated solution seeks to dilute the more concentrated so-

Table 1. Comparative between many pilot projects.

\begin{tabular}{|c|c|c|c|c|c|}
\hline Batteries (kWh) & PV (kW peak) & Capacity $\left(\mathrm{m}^{3} / \mathrm{d}\right)$ & Feed Water (ppm) & References & Location \\
\hline 880 & 100 & 40 & Seawater & Sardi 1996; via CRES (1998) & Lampedusa, Italy \\
\hline 44 & & & & (Herold et al. 1998) & \\
\hline \multirow[t]{2}{*}{19} & 4.8 & 3 & Seawater & (Herold et al. 2001) & ITC, Canaries (DESSOL) \\
\hline & & & & (Espino et al. 2003) & \\
\hline Yes & 5 to 25 & 4 to 19 & 32,000 & (Kunczynski 2003) & La Paz, Mexico \\
\hline
\end{tabular}




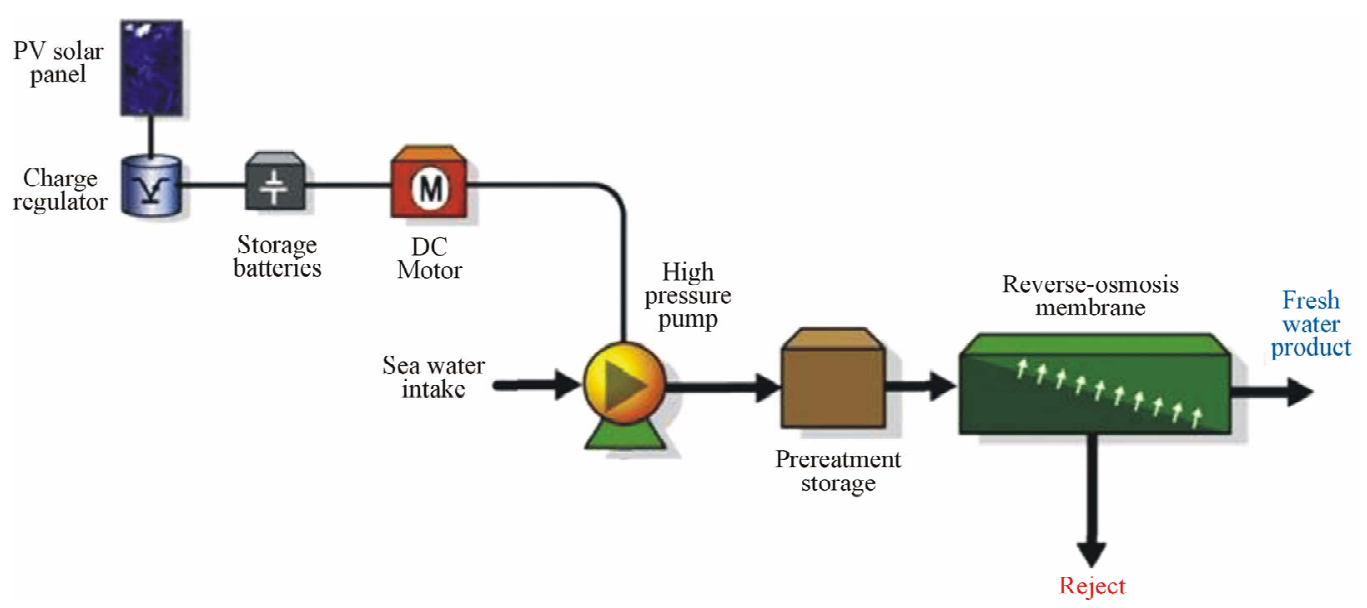

Figure 1. The component of PV-RO system.

lution, water will pass through the membrane from the lower concentration side to the greater concentration side. Eventually, osmotic pressure seen in Figure 2 as the pressure created by the difference in water levels) will counter the diffusion process exactly, and equilibrium will be formed.

The process of reverse osmosis forces water with a greater concentration of contaminants (the source water) to go into a tank containing water with an extremely low concentration of contaminants (the processed water). High water pressure on the source side is used to "reverse" the natural osmotic process, Figure 3, with the semi-permeable membrane still permitting the water to pass while rejecting most of the other contaminants. The specific process through which this occurs is called ion exclusion, in which a concentration of ions at the membrane surface from a barrier that allows other water molecules to pass through while excluding other substances.

Semi permeable membranes have come a long way from the natural pig bladders used in the earlier osmosis experiments. Before the 1960 's, these membranes were too inefficient, expensive, and unreliable for practical applications outside the laboratory. Modern advances in synthetic materials have generally solved these problems, allowing membranes to become highly efficient at rejecting contaminants, and making them tough enough to withstand the greater pressures necessary for efficient operation.

Even with these advances, the "reject" water on the source side of a Reverse Osmosis (RO) system must be periodically flushed in order to keep it from becoming so concentrated that it forms a scale on the membrane itself. RO systems also typically require a carbon pre filter for the reduction of chlorine, which can damage an RO membrane; and a sediment pre filter is always required to ensure that fine suspended materials in the source water do not permanently clog the membrane. Hardness reduction, either through the use of water softening for resi-

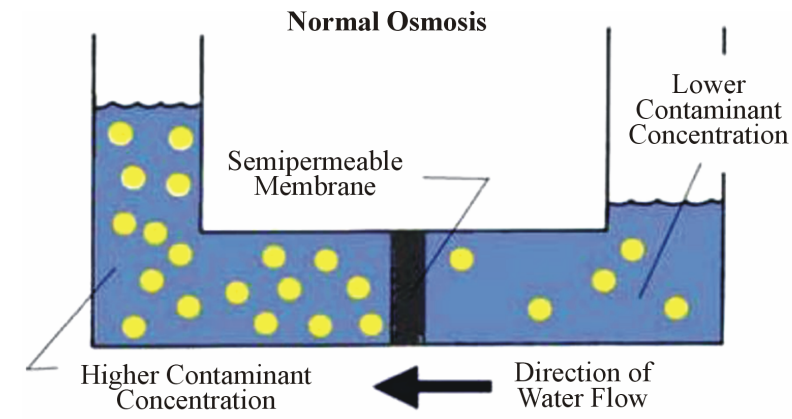

Figure 2. Natural osmosis.

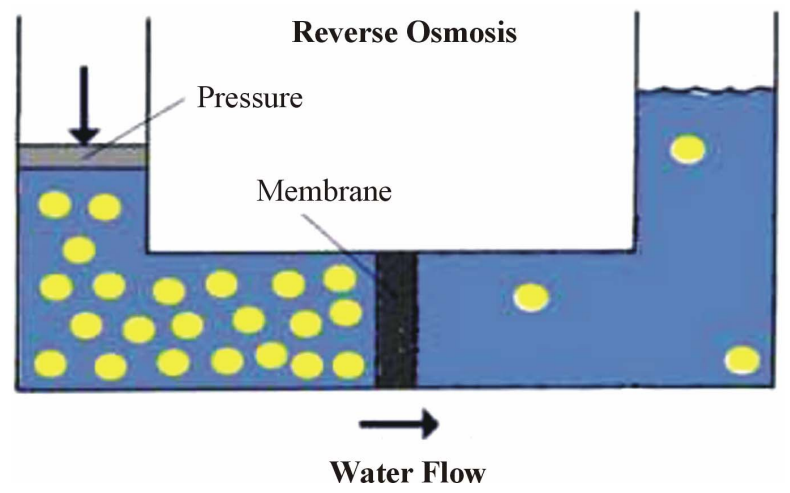

Figure 3. Reverse osmosis.

dential units or chemical softening for industrial use, may also be desirable in hard water areas [3].

We have many types of RO membrane:

1) Tubular Membranes.

2) Capillary Membranes.

3) Hollow Fiber Membrane.

4) Spiral Membrane.

The used membrane that is used in this paper is Spiral membrane, So it's important to expand in it: Commercially marketed spiral-wound membrane elements (e.g., spiral-wound RO elements) are operated with only one stream (the feed stream) flowing under direct control of 
its flow velocity tangential to the membrane. The permeate stream flows very slowly in the channel formed by the two glued membranes and its composition and flow velocity are controlled by the properties of the membrane and the operating conditions [4].

\subsection{Photo-Voltaic Modules}

Photo-Voltaic (PV) can be thought of as a direct current (DC) generator powered by the sun. When light photons of sufficient energy strike a solar cell, they knock electrons free in the silicon crystal structure forcing them through an external circuit (battery, inverter or direct DC load), and then returning them to the other side of the solar cell to start the process all over again, Figure 4. The voltage output from a single crystalline solar cell is about $0.5 \mathrm{~V}$ with an amperage output that is directly proportional to the cell's surface area (approximately 7A for a 6 inch square multi-crystalline solar cell). Typically 30 - 36 cells are wired in series ( + to - ) in each solar module. This produces a solar module with a $12 \mathrm{~V}$ nominal output $(\sim 17 \mathrm{~V}$ at peak power) that can then be wired in series and/or parallel with other solar modules to form a complete solar array.

The cost of PV has fallen steadily, and this is expected to continue for several years yet. The cost today is still considerable, but there are many situations where PV already offers a cost-competitive solution, although, to make this apparent, it is usually necessary to consider the full lifetime costs of the alternatives. Life-cycle costing is a standard accounting technique and can readily be applied to PV systems (Markvart 1999 page 148).

Often the choice is between PV and diesel-fed internal combustion engines. The latter are typically very cheap to buy but expensive to operate, both in fuel and maintenance. The operating costs of diesel engines per $\mathrm{kWh}$ increase dramatically as the average demand $(\mathrm{kWh} /$ day) is reduced. In contrast, PV costs per $\mathrm{kWh}$ are almost constant, and thus, PV becomes competitive below a certain average demand (kWh/day). Parish (1999) showed that the crossover point can be between 2.5 and $5 \mathrm{kWh} /$ day,

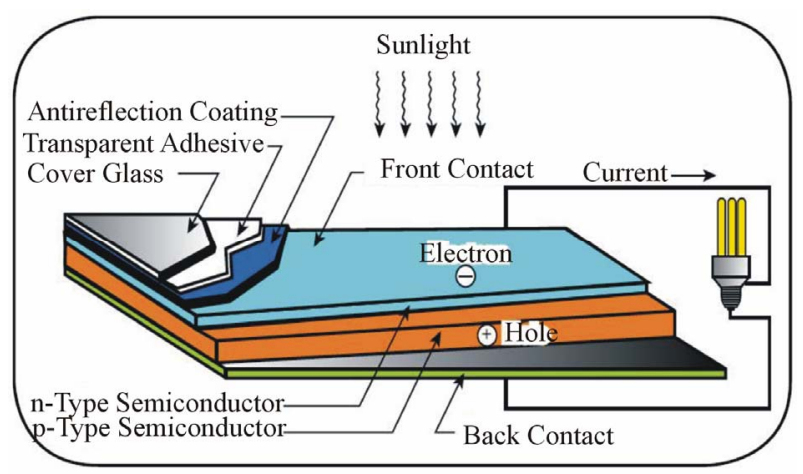

Figure 4. Photo-voltaic cell. depending on PV costs $25(\$ / W p)$ and diesel costs Figure 5. A far more detailed study, using data specific to India, showed a much higher crossover point: between 15 and $68 \mathrm{kWh} /$ day (Kolhe et al. 2002). Both of these studies include substantial costs for batteries and battery replacement in the PV systems. For applications that do not require batteries, the crossover point is higher still. Nonetheless, there is still a crossover point, above which a diesel engine is more economic, excluding environmental considerations. In summary, PV is most competitive for systems with modest average demand, and thus PV-RO will be most competitive, initially at least, in small-scale.

Even using life-cycle costing, the PV often dominates the costs of a proposed system. This focuses attention on maximizing the efficiency of the load to a far greater extent than might be pursued if operate from grid electricity or diesel. Indeed, much of the design effort described in this thesis relates to improving the efficiency of the load, in this case a small RO system [5].

\section{PV-RO Model}

Our model shown in Figure 6.

Design and sizing of the PV-powered RO desalination systems depend mainly on the daily fresh water requirement, salinity of brackish water and the climate parameters on the plant site which are illustrated in following Table 2.

The main goal of system sizing is to achieve the right balance between daily needs of electrical energy consumed by the loads and daily produced electrical energy

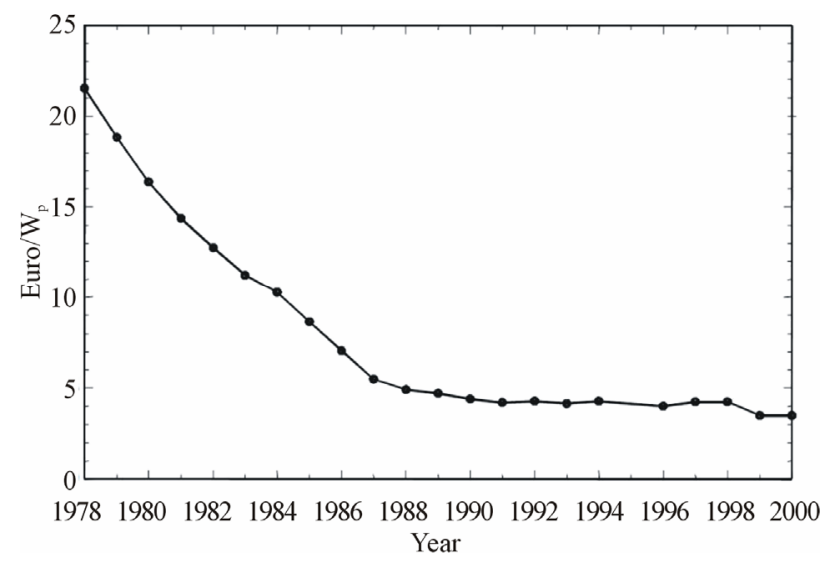

Figure 5. Cutting down PV cost.

Table 2. Water and climate parameters.

\begin{tabular}{cc}
\hline $600 \mathrm{mg} / \mathrm{l}(\mathrm{ppm})$ & Salinity of brackish water \\
\hline $1200 \mu \mathrm{s} / \mathrm{cm}$ & Conductivity
\end{tabular}

$30^{\circ} \mathrm{C} \quad$ Fresh water requirement (daily average) 
by the PV generator. To achieve this we should start with the loads. The daily consumed electrical energy by the loads has to be identified at the beginning of system sizing, so as to calculate the daily needed PV electrical energy and the total peak power of the PV generator.

\subsection{Sizing the RO System}

The concentrate of feed water of laboratorial model 600 $\mathrm{mg} / \mathrm{L}$, So we choose membrane from DOW company. As result we don't need to produce large amount from freshwater; $\mathrm{SO}$ we choose affordable local membrane TW301812-100, its specifications illustrated in the following Table 3: [6].

\subsection{Sizing the Brackish Water Pumping System}

We must calculate the required hydraulic power to be able to estimate the suitable motor which drive the pump; So we need the maximum required Flow which is 100 gpd $=0.07 \mathrm{gpm}$, and the maximum required pressure which is $16 \mathrm{bar}=50$ psi Figure 7: [7].

$$
\text { Phydrolic }=\frac{\text { Flow Rate }(\text { gpm }) \times \text { Pressure }(\mathrm{psi})}{1714 \times \mu}
$$

$$
\begin{gathered}
\text { Phydrolic }=\frac{0.07(\mathrm{gpm}) \times 50(\mathrm{psi})}{1714 \times 0.6}=0.034 \mathrm{HP}=26 \mathrm{~W} \\
\text { Pelec }=\frac{0.252}{0.9}=0.038 \mathrm{HP}=29 \mathrm{~W}
\end{gathered}
$$

\subsection{Sizing the Storage Battery Block}

To determine the capacity of battery block, we need the storage days which calculate from the following equation for $95 \%$ and $99 \%$ standby:

$$
\begin{aligned}
& \text { Storage days }(99)=24-4.73(\mathrm{PSH})+0.3(\mathrm{PSH})^{2} \\
& \text { Storage days }(95)=9.43-1.9(\mathrm{PSH})+0.11(\mathrm{PSH})^{2}
\end{aligned}
$$

But in this application, we don't need high standby, So we choose $95 \%$ standby and consider the $\mathrm{PSH}=5.2$ $\mathrm{kw} / \mathrm{m}^{2}$ :

$$
\begin{aligned}
\text { Storage days }(95) & =9.43-1.9(5.02)+0.11(5.02)^{2} \\
& =2.66 \text { Days }
\end{aligned}
$$

The required daily DC energy will equal:

$$
\begin{aligned}
& E_{D C}=\text { Pelec } 24 \mathrm{~h} / \text { day }=696 \mathrm{Wh} / \mathrm{d} \Rightarrow \\
& A h_{D C}=\frac{696}{24}=29 \mathrm{Ah} / \mathrm{d}
\end{aligned}
$$

Usable battery capacity $=29 \mathrm{Ah} / \mathrm{d} \times 2.66=77.14 \mathrm{Ah}$

Nominal battery capacity $=\frac{77.14}{0.8 \times 0.97}=99.4 \mathrm{Ah}$ at $24 \mathrm{~V}$

\subsection{Roughly Way to Estimate PV Array}

We need here to determine the slope degree; as known and as we see when the slope degree is $30^{\circ}$ Figure 8 . We

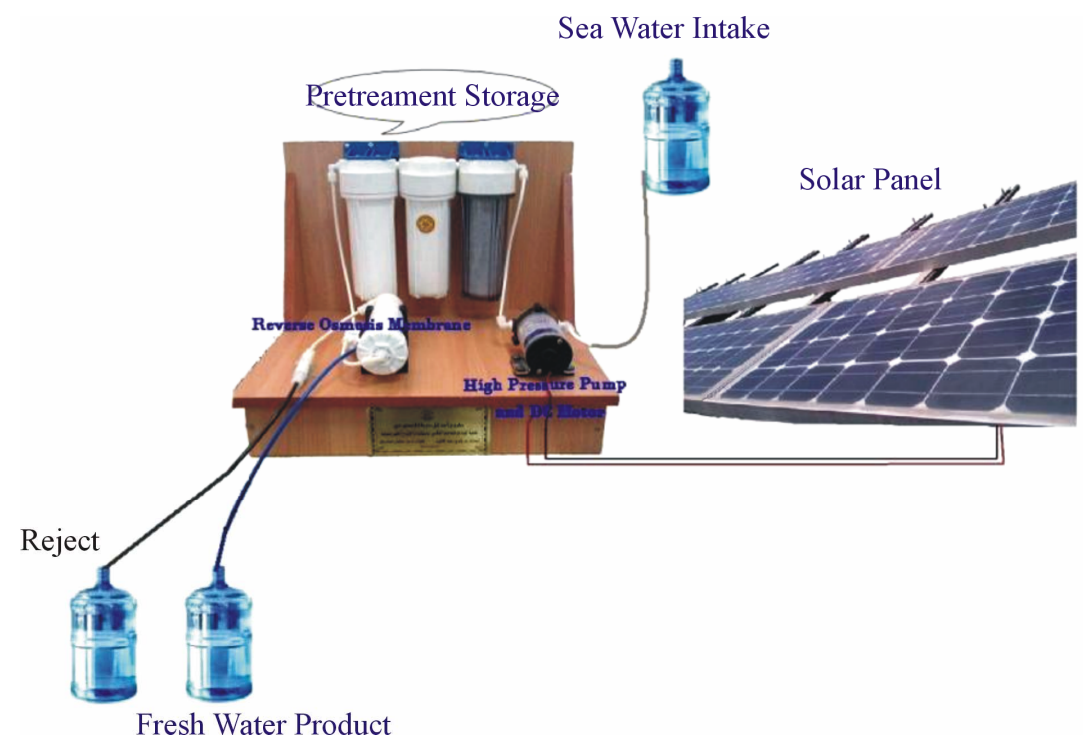

Figure 6. The proposed practical model.

Table 3. Membrane specifications.

\begin{tabular}{ccccc}
\hline Stabilized salt rejection (\%) & Permate flow rate gpd (llh) & Applied pressure psig (bar) & Part number & Product \\
\hline 90 & $100(16)$ & $50(3.4)$ & 170,102 & TW30-1812-100 \\
\hline
\end{tabular}


choose February as design month because it is the worse month in solar radiation, as illustrated in Figure 9.

The distance between the rows is indicated according the equations:

$$
Y=\frac{\Delta I \times(180-\beta)}{f_{\text {diff }}}
$$

$Y=$ Shadowing degree

$\Delta I=$ Reducing in the value of radiation produced from the shadowing (usually $7.5 \%$ ).

$\beta=$ Slope degree.

$f_{\text {diff }}=$ the ratio between the diffused and total radiation on the surface (usually 0.46 ).

\subsubsection{With Battery}

As shown in Figure 10 the average of daily solar energy in Damascus [8];

$$
\begin{gathered}
P S H=\frac{E_{D C}}{G_{o}} \\
P S H=\frac{5179}{1000}=5.2 \mathrm{~h}
\end{gathered}
$$

The required $P V$ illustrated in the following equation;

$$
P_{P V}=\frac{1.25 \times E_{P V}}{P S H} \Rightarrow
$$

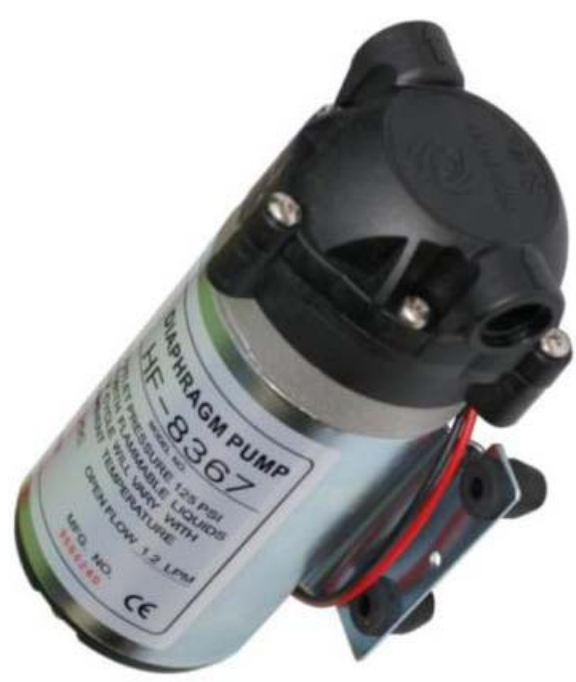

Figure 7. The motor-pump combination.

$$
P_{P V}=\frac{1.25 \times 0.696}{5.2}=0.167 \mathrm{KW}
$$

As we see in the Table 4 there are many factors affect in the performance of PV modules, So:

$$
\begin{aligned}
& \text { N. of module }=\frac{P_{P V}}{0.78 \times P_{\text {MODULE }}} \Rightarrow \\
& \text { N. of module }=\frac{0.167}{0.78 \times 0.05}=4.3 \text { Module }
\end{aligned}
$$

\subsubsection{Without Battery}

In this way, we must determine the solar current

$$
\begin{gathered}
I_{S}=1.353 \times 0.7^{A M^{0.678}} \times 1.1 \times \sin (\alpha+\beta) \\
A M=\frac{1}{\cos \alpha}=1.197
\end{gathered}
$$

Then:

$$
I_{S}=1.353 \times 0.7^{1.197^{0.678}} \times 1.1 \times \sin (33.32+30)=99 \mathrm{mw} / \mathrm{cm}^{2}
$$
we should calculate the maximum power point current for $100 \mathrm{w} / \mathrm{cm}^{2}$ :

$$
I_{m p}=\frac{1.2 \times 100}{0.8 \times 99}=1.5 \mathrm{~A}
$$

where 1.2 is the motor current.

Regarding the factors in Table 4, and when we consider 0.95 is the ratio between the short circuit current and the maximum power point current:

$$
I_{S C}=\frac{1.5}{0.95 \times 0.78}=2 \mathrm{~A}
$$

Number of string $=\frac{I_{S C}}{I_{S C-P V}}=\frac{2}{3.3}=0.9$ Strings

Table 4. The effected factors on the PV modules.

\begin{tabular}{cc}
\hline Reducing Factor & Consideration \\
\hline 0.95 & STC \\
0.89 & Cell Temperature \\
0.93 & Fouling factor \\
0.78 & Total \\
\hline
\end{tabular}

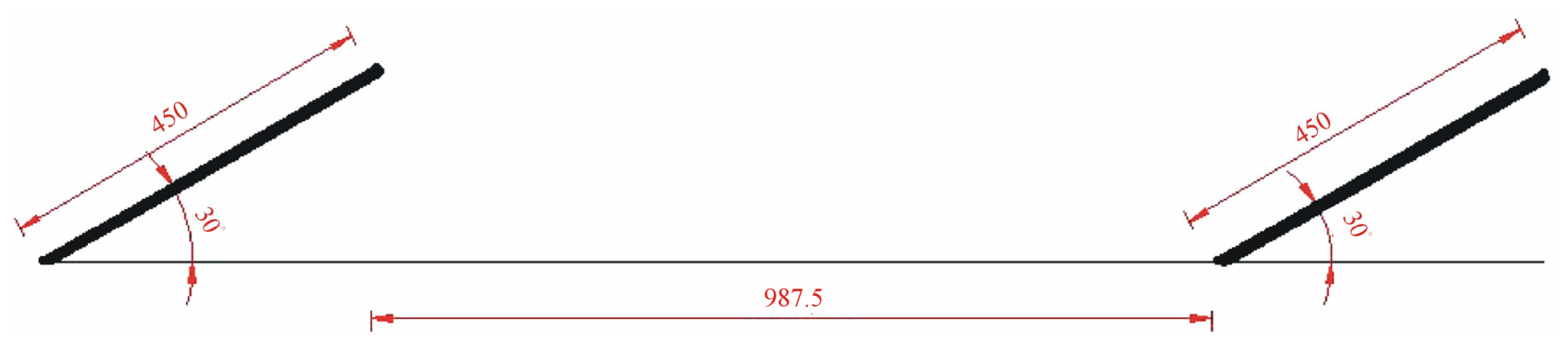

Figure 8. Angle module and distance with other one. 


\begin{tabular}{|c|c|c|c|c|c|}
\hline \multicolumn{6}{|c|}{ Components of Radiation on Tilted Surface Calculator } \\
\hline Array Tilt, $\beta=$ & 30 & degrees. & Declination, $\delta=$ & -23.18 & \multirow{4}{*}{$\begin{array}{l}\text { degrees } \\
\text { degrees. }\end{array}$} \\
\hline Latitude, $\varphi=$ & 33.5 & degrees. & Sun Angle, $a=$ & 33.32 & \\
\hline \multirow{2}{*}{\multicolumn{3}{|c|}{$\begin{array}{l}\text { Hemisphere: } \sigma \text { North } C \text { South } \\
\text { Day Number, } d=346\end{array}$}} & & & \\
\hline & & & & & \\
\hline
\end{tabular}

\begin{tabular}{|c|c|c|c|}
\hline$S_{\text {horiz }}=5106$ & Calculate & $S_{\text {module }}=8306.2$ & $S_{\text {incident }}=9296.33$ \\
\hline$S_{\text {incident }}=9296.33$ & Calculate & $S_{\text {horiz }}=5106$ & $S_{\text {module }}=8306.21$ \\
\hline$S_{\text {module }}=8306.2$ & Calculate & $S_{\text {horiz }}=5106$ & $S_{\text {incident }}=9296.32$ \\
\hline
\end{tabular}

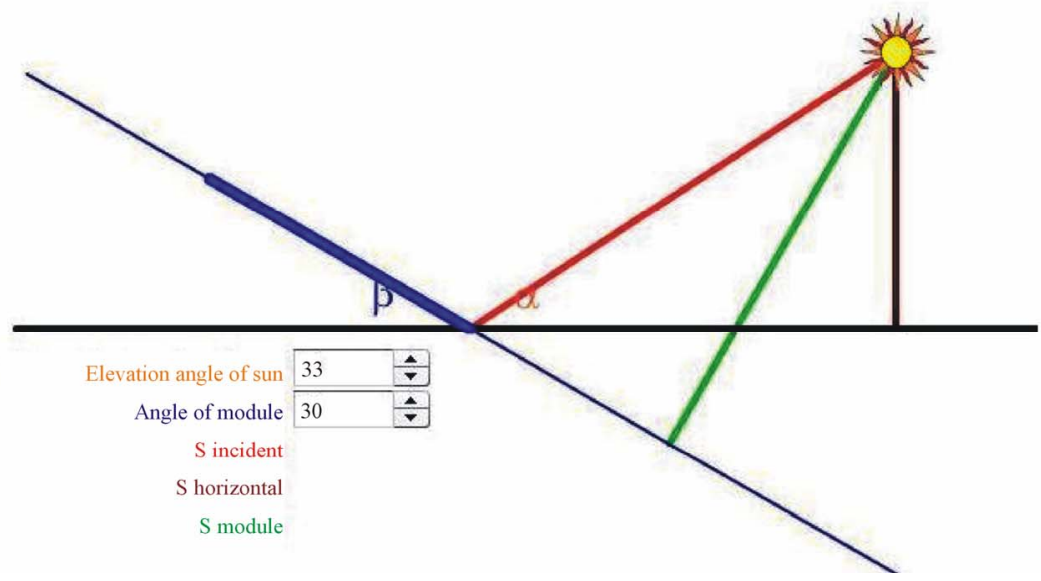

Figure 9. The solar radiation.

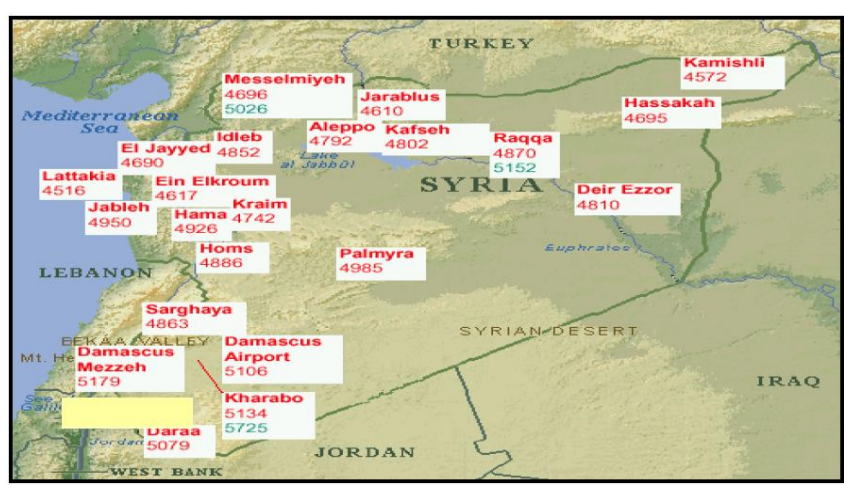

Figure 10. Mean annual daily radiation on horizontal surface $W h / \mathbf{m}^{2}$.

Quantity of product water per day

$$
=\frac{100 \times 5.2}{24}=2.16 \mathrm{gpd}=100 \mathrm{~d} / \mathrm{L}
$$

\section{Results}

The laboratorial model connection illustrated in the following Figure 11 with required instrumentations. We get the following results: Figures 12-14. I see that the voltage generated from the PV modules is constant, because the maximum power point voltage is unaffected with the variables of radiation.

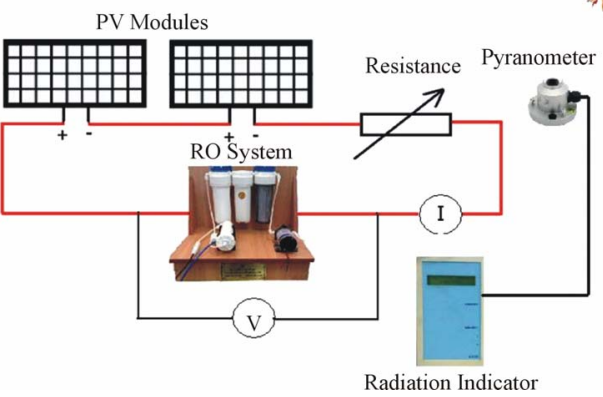

Figure 11 . The diagram of testing the model. 


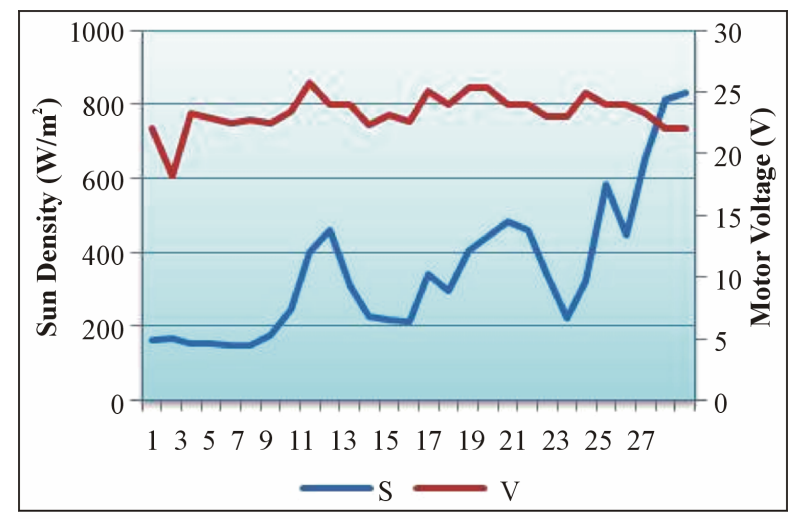

Figure 12. The variations of solar density and motor voltage.

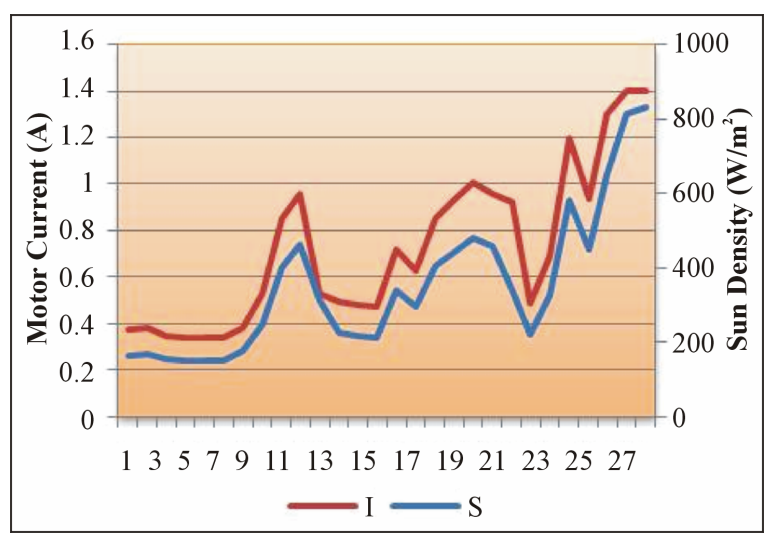

Figure 13. The variations of solar density and motor current.

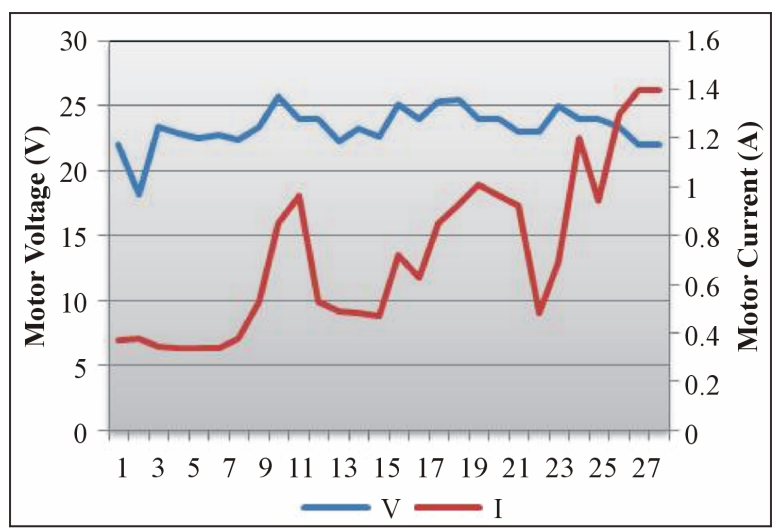

Figure 14. The variations of motor current and motor voltage.
We observe that the current vary with the variations of solar radiation.

\section{REFERENCES}

[1] A. M. Thomson, "Reverse-Osmosis Desalination of Seawater Powered by Photovoltaic without Batteries," Loughborough University, A Doctoral Thesis, 2003, p. 41.

[2] A. Shakouri, "Desalination by Reverse Osmosis Powered with Photo-Voltaics," A Prototype for Jordan on the Example of California, Local Renewable Energy Summer Research Program, 2009, p. 13.

[3] "How Reverse Osmosis Works." http://www.wqa.org/sitelogic.cfm? ID=872

[4] T. Y. Cath, A. E. Childress and M. Elimelech, "Review Forward Osmosis: Principles, Applications, and Recent Developments," Journal of Membrane Science, Vol. 281, No. 1-2, 2006, pp. 70-87. http://dx.doi.org/10.1016/j.memsci.2006.05.048

[5] "Solar Electric Products Catalog," Kyocera.

[6] Data Sheet of TW30-1812-100 Membrane.

[7] Data Sheet of Diaphragm Pump HF-8367.

[8] F. Aljawabra, "Large Scale RE Projects in Syria-An Analysis of the Institutional and Legal Framework in View of the Egyptian Experience," Cairo University, Master Thesis, 2011, p. 30. 